\title{
On the Trade Balance Response to Monetary Shocks : the Marshall-Lerner Conditions Reconsidered
}

\author{
Giovanni Lombardo \\ Trinity College, Dublin
}

\begin{abstract}
This paper studies the applicability of the Marshall-Lerner condition to the "basic" Obstfeld and Rogoff (1995) model. It shows that the Marshall-Lerner condition does apply to this class of models with homothetic preferences when product differentiation across countries is imposed. This paper also shows that, in certain cases, the intertemporal substitution and the dynamic income effect can make the mere elasticity of substitution an insufficient indicator of the response of the current account to monetary shocks.
\end{abstract}

JEL Classifications: C6, E3, E4

Key words: Trade balance, Marshall-Lerner conditions, Elasticity of substitution, Monetary shocks, Transfer problem

*Corresponding address: Giovanni Lombardo, Department of Economics, Trinity College Dublin, Dublin 2 - Rep. of Ireland, Tel: +353-1-6081041, Email: lombarg@tcd.ie 


\section{Introduction}

One of the most famous concepts in international economics is the Marshall-Lerner (ML) condition. This is the description of the relationship between the Current Account and the relative price of traded goods. With this condition, in principle, one should be able to predict the change in the Current Account knowing the elasticities of import and export and the direction of change of the relative price.

Recent international macroeconomic literature has developed models based on the seminal work of Obstfeld and Rogoff (1995), that is a dynamic general equilibrium two-country model with imperfect competition and fixed prices aimed at analysing (primarily) the macroeconomic consequences of monetary shocks. In that formulation, as in many extensions of that model ${ }^{1}$, it was assumed that consumers perceive goods to be differentiated across firms but not across countries. This assumption, together with the Dixit-Stiglitz demand structure (Dixit and Stiglitz, 1977) implies that the ML condition is always satisfied. Clearly this is not very satisfying from a theoretical point of view.

On this regard, the claim by Backus et al. (1994) that the ML condition cannot be applied in models with homothetic preferences assumes particular relevance. In our paper we will reconsider this claim within the Obstfeld and Rogoff (1995) class of models where homothetic preferences are used. In particular we will examine to what extent the ML condition gives information on the response of the current account to monetary shocks. We will show that while the ML condition still applies, the dynamic structure of Obstfeld and Rogoff's approach brings about other factors, which can influence the response of the current account ${ }^{2}$

Our paper modifies the Obstfeld and Rogoff (1995) setup slightly. While we keep the structure of the model fairly simple, e.g. neglecting capital accumulation and more complex price adjustment mechanisms, we modify the demand structure of the model to include product differentiation across countries. This amounts to imposing the Armington assumption widely used

\footnotetext{
${ }^{1}$ See Obsfeld and Rogoff (1996, chapter 10), Betts and Devereux (1996) and Lane (1999b). In the appendix of a more recent paper Obstfeld and Rogoff (1998) assume product differentiation across countries

${ }^{2}$ The effects of monetary shocks on the current account have been recently analysed, among others, by Lane (1999a) and Devereux (1999). The latter does also make explicit reference to the Marshall-Lerner conditions. Devereux uses "pricing-to-market" goods. The consequence of this is to involve the inter-temporal elasticity, together with the intratemporal elasticity of substitution in the determination of the response of the CA. Lane (1999b) has tradable and non tradable goods. The Marshall-Lerner conditions in that context do also involve the relative magnitude of the intertemporal/intra-temporal elasticity of substitution, although not always in an identical way.
} 
in Computable General Equilibrium models. ${ }^{3}$ Contrary to the CGE and AGE literature we neglect differences in the degree of substitutability between goods across industries. While these differences might be marked and important as reported by Shiells and Reinert (1993) and Bloningen and Wilson (1999), they are typically neglected by the New-Open Economy literature for tractability reasons. ${ }^{4}$ Also in contrast with the trade literature we will neglect the home bias assumption that typically accompanies the Armington assumption. ${ }^{5}$ This paper is purely theoretical. The actual response of the current account to monetary shocks is ultimately an empirical issue. Our model shows that the degree of substitution among goods, together with intertemporal decisions by the agents, are some of the mechanisms on which the observed response of the current account is likely to depend. Product differentiation among countries in our setup opens up the possibility of negative responses of the current account to a monetary shock. This does not imply that we believe in a negative correlation between monetary shocks and the current account. While the current account is deemed by many researchers to be countercyclical ${ }^{6}$, some evidence suggests that it is positively correlated with money (e.g. Lane 1999a). Our paper therefore re-proposes the traditional view of the current account dynamics in which the Marshall-Lerner condition plays a crucial role.

Chari et al. (1997) build a quantitative model of exchange rate variation very close to the analytical framework of Obstfeld and Rogoff (1995) and where a demand structure similar to ours is adopted. They reach the conclusion that the counter-cyclical dynamics of the trade balance can

\footnotetext{
3 FFor a general discussion of this issue in CGE and AGE models see Francois and Shiells (1994). See also de Melo and Robinson (1989) and Trefler (1995). For an empirical investigation of this functional form see Shiells and Reinert (1993) and Blonigen and Wilson (1999).

${ }^{4}$ Shiells and Reinert (1993) report on various CGE studies where a nested specification of preferences very similar to the one adopted here is used. The main result in relation to the nested specification is that the welfare consequences of trade agreements are sensitive to the relative elasticity of substitution across countries vis-à-vis within countries. While similar considerations might produce interesting results for macroeconomic analysis, they would involve much more complex models, which are beyond the scope of the present work.

${ }^{5}$ Trefler (1995) shows that the home bias assumption typical of the Armington demand structure fares better in explaining international trade than the standard Heckscher-Ohlin-Vanek assumption. While home bias could be incorporated in our macro-model we want to keep our model as close to the Obstfeld and Rogoff (1995) setup as possible to highlight the basic issue of the Marshall-Lerner conditions in New-Open Economy models.

${ }^{6}$ This is often referred to as a "stylised fact" although there is some variation in the empirical evidence. See for example Danthine and Donaldson (1993), Backus et al. (1994a,b), Baxter and Crucini (1993), Kollmann (1997). As for Chari et al. $(1997,1998)$ they refer to this regularity in their 1997 version although the tables reported in the second version show the opposite: a positive correlation between output and net export (over output) for 8 out of 10 countries (one is aggregate Europe). Mendoza (1995) also reports a positive correlation between net export (over output) and output for G7 countries except for the U.S.A., which shows a negative correlation. The other groups of countries listed by Mendoza ( 25 countries) show only 5 countries with a positive correlation.
} 
be matched only by considering capital accumulation. ${ }^{7}$ Chari et al. do not raise the issue of the validity of the ML conditions and whether they are satisfied or not.

Corsetti and Pesenti (1997) also highlight the unnecessary restriction imposed on the demand structure in the earlier Obstfeld and Rogoff type of papers. Nevertheless they prefer to use a Cobb-Douglas aggregation function among domestic and imported goods. This imposes a unitary elasticity of substitution between domestic and imported goods and hence it "cuts off" the current account dynamics.

Our paper is very closely related to the work of Tille (1999). He too shows that disentangling the elasticity of substitution between domestic and imported goods from the markup parameter yields a wider range of results as compared with the original Obstfeld and Rogoff (1995) model. His analysis is aimed at deriving the conditions under which monetary and fiscal shocks affect domestic and foreign welfare in different ways.

The rest of the paper is organized as follows. In section (1) we highlight the general issue of the Marshall-Lerner conditions and present and discuss the nested CES aggregation function. In section (2) we re-write the original Obstfeld and Rogoff (1995) model (OR henceforth) using the nested CES function to derive, in section (3) the conditions for a negative response of the current account. Some remarks and conclusions follow in section (4).

\section{Elasticity of substitution and degree of competition}

\section{The Marshall-Lerner condition: I}

Traditionally, and in a static context, the relation between the real exchange rate and the trade balance is described by the Marshall-Lerner condition ${ }^{8}$. This states that if the sum of the elasticity of exports with respect to the real exchange rate and the elasticity of imports is bigger than one, then we should expect a real depreciation of the exchange rate to produce an improvement of the trade balance (and the current account) ${ }^{9}$ (Krugman and Obstfeld, 1997, p. 483).

\footnotetext{
${ }^{7}$ In a recent revised version of their paper, Chari et al. (1998) drop altogether the argument on the countercyclicality of the current account focusing only on the volatility of the real exchange rate.

${ }^{8}$ In relation to modelling strategies, we adopt the viewpoint of the New-Open Economy literature, i.e. a macroeconomic perspective. We largely neglect the trade literature and the CGE models, which are typically developed along different dimensions. The interested reader is referred to the brief discussion in the introduction to this paper and to the literature cited therein.

${ }^{9}$ For small shocks around a balanced current account.
} 
Ethier (1988, p. A-17) shows that when two countries have identical tastes the MarshallLerner conditions are always satisfied. ${ }^{10}$ General equilibrium models of the current account typically make use of homothetic preferences over consumption goods that are identical across countries. Hence, following Ethier (1988), the ML condition should always be satisfied. Yet, we show that the current account can deteriorate consequent upon a monetary shock and, thus, upon a depreciation of the domestic currency under the OR assumptions ${ }^{11}$.

The textbook ML condition does generally refer to the mere "substitution effect" of terms of trade variation on export and import demands. If we are interested on the actual response of the trade balance to terms of trade variations we should study the total effect of a terms of trade variation on the trade balance, i.e. including possible "income effects" of such variation"

In the remaining of this paper we will refer to the ML condition as to the condition that governs the actual response of the trade balance to an exchange rate variation.

The ML condition is easily derived from the real trade balance equation $(T B),{ }^{13}$ defined as total export minus total import

$$
T B=\frac{P_{h}}{P} E X-E \frac{P_{f}}{P} I M
$$

where $P_{\mathrm{h}}$ is the price of exported goods, $P_{\mathrm{f}}$ is the price of imported goods in foreign currency, $E$ is the exchange rate and $P$ is the domestic price index. If we normalize by the relative price of exported goods, we can rewrite the last expression as

\footnotetext{
${ }^{10}$ The reference is suggested in Backus et al. (1994 p.79) who state “... the Marshall-Lerner condition is always satisfied when consumers in the two countries have identical homothetic preferences"

${ }^{11}$ Devereux (1999) referring to the ML conditions does restrict his attention only to the "substitution effect" of a currency depreciation. As explained below, this is possibly the standard interpretation of the ML conditions (see Krugman and Obstfeld, 1997 p. 483). As such this definition is incomplete if one is interested in the actual response of the trade balance to exchange rate variations. Nevertheless, as we show in this work, Devereux's condition is a good approximation of the actual ML conditions applied in the OR context.

${ }^{12}$ The relation between the terms of trade and the trade balance has also been studied under the so called "LaursenMetzler effect" (see Obstfeld, 1982). This literature studies the relation between terms of trade variations and the behaviour of saving (consumption). As Obstfeld (1982) reminds us, if, for example, consumption is rather constant, a deterioration in the terms of trade that reduces real income will bring about a reduction in saving and thus, ceteris paribus, a trade deficit. This channel is also important in our model, since saving decisions are affected by future wealth and hence by terms of trade variations.

${ }^{13}$ The effect on the CA of a relative price variation is predicted by the ML condition once the variation on the other components of the current account are taken into consideration, e.g. the change in interest flow on the existing foreign debt. In this work we concentrate on the impact effect of a currency depreciation on the current account around a symmetric equilibrium, i.e. with zero outstanding debt.
} 


$$
T B=\frac{P_{h}}{P}(E X-R I M)
$$

where $R=E \frac{P_{f}}{P_{h}}$ is the real exchange rate. A change in the $T B$, around its equilibrium level, due to a change in the relative price of imported goods is given by the following equation

$$
\frac{d T B}{d R}=\frac{d E X}{d R}-I M-R \frac{d I M}{d R}
$$

Since we consider $T B$ deviations from its equilibrium, assuming that the real exchange rate is 1 , then $E X=I M$, and we can collect $I M$ to obtain

$$
\frac{d T B}{d R}=\left(\varepsilon_{E X}-\varepsilon_{I M}-1\right) I M
$$

Assuming that import decreases with a depreciation, then the $T B$ improves after a relative price increase (a currency depreciation) if

$$
\varepsilon_{E X}+\left|\varepsilon_{I M}\right|>1
$$

which is the well-known ML condition.

Let's define the demand for import as $I M=I M\left(\frac{P_{h}}{E P_{f}}, D_{h}\right)$ where $D$ stands for total demand. Analogously the demand for export is defined as $E X=E X\left(\frac{E P_{f}}{P_{h}}, D_{f}\right)$. The elasticities in the ML condition are therefore made up of a substitution effect, i.e. $E X_{1}$, and an income effect, i.e. $E X_{2}{ }^{14}$ In the rest of the paper we will show that under the OR assumptions, the income effect is negligible and that the substitution effect dominates the ML condition. The latter is not satisfied if the domestic goods are poor substitutes for the foreign goods.

\section{Degree of competition disentangled}

The typical consumption index used by OR models is the homothetic aggregation function yielding constant elasticity of substitution (CES) i.e.

\footnotetext{
${ }^{14}$ The subscript denotes the variable of derivation.
} 


$$
C=\left(\int_{0}^{1} c_{i}^{\theta} d i\right)^{\frac{1}{\theta}}
$$

where the range of the variety is normalized to the continuous segment $(0,1)$.

In a two-country model it is then assumed that $n$ goods are produced at home and $(1-n)$ abroad, where $n \in(0,1)$. Thus the index can be rewritten as follows

$$
C=\left(\int_{0}^{n} c_{i}^{\theta} d i+\int_{n}^{1} c_{j}^{\theta} d j\right)^{\frac{1}{\theta}}
$$

with the associated demands for individual goods

$$
\begin{aligned}
& c_{i}=\left(\frac{p_{i}}{P}\right)^{\frac{1}{\theta-1}} C \\
& c_{j}=\left(\frac{p_{j}}{P}\right)^{\frac{1}{\theta-1}} C
\end{aligned}
$$

where $p_{i}$ and $p_{j}$ are the home currency prices for good $i$ and $j$ respectively and $P$ is the price index which we do not define for the moment.

Clearly, since $\frac{1}{1-\theta}$ is the elasticity of the demand faced by the monopolistic firm, it must be $\frac{1}{1-\theta}>1$. But since this measure is also the elasticity of substitution between domestic and imported goods, namely

$$
-\frac{d \log \frac{c_{i}}{c_{j}}}{d \log \frac{p_{i}}{p_{j}}}=\frac{1}{1-\theta}
$$

we are unnecessarily restricting the elasticity of inter-country substitution.

We can easily disentangle the two elasticities by nesting two levels of CES functions, namely 


$$
C=\left\{n^{1-\theta} C_{h}^{\theta}+(1-n)^{1-\theta} C_{f}^{\theta}\right\}^{\frac{1}{\theta}}
$$

where

$$
C_{h}=\left(n^{\omega-1} \int_{0}^{n} c_{i}^{\omega} d i\right)^{\frac{1}{\omega}}
$$

and

$$
C_{f}=\left((1-n)^{\omega-1} \int_{n}^{1} c_{j}^{\omega} d j\right)^{\frac{1}{\omega}}
$$

where $c_{i}$ and $c_{j}$ are goods produced at home and abroad, respectively. The weights given to home and foreign goods in equation (2) have an important and twofold meaning. To see this let us consider first equations (3) and (4). There the coefficient $n$ and (1-n) normalize the aggregation function to the variety of goods supplied by each country, furthermore it eliminates the "taste for variety" from the aggregation function. In equation (2) the same coefficients determine the bias of the consumption bundle towards a particular country: i.e. when $n=0.5$ the two countries are equally represented in the aggregation function. Generally the two concepts, "love for variety" and countrybias are independent, so that consumers might prefer the goods produced in a specific country despite the smaller variety of goods supplied by that country as compared with the other country (e.g. rest of the world). As is typical in dynamic general equilibrium models, our model is solved by linearization around the symmetric steady state, i.e. where the current account is balanced. For this purpose, the bias needs to be reduced to the mere condition that all individuals consume all goods. This is to say that if all the goods of each country are consumed in equal quantity, each individual consumes $n$ goods of the Home country and (1-n) of the foreign country, i.e. exactly equal to the variety offered by each country.

The demand functions associated with this consumption indexes are ${ }^{15}$

$$
C_{h}=n\left(\frac{P_{h}}{P}\right)^{\frac{1}{\theta-1}} C
$$

\footnotetext{
${ }^{15}$ Notice that $c_{i} / c_{j}$ is independent from income.
} 


$$
\begin{aligned}
& C_{f}=(1-n)\left(\frac{E P_{f}}{P}\right)^{\frac{1}{\theta-1}} C \\
& c_{i}=\frac{1}{n}\left(\frac{p_{i}}{P_{h}}\right)^{\frac{1}{\omega-1}} C_{h} \\
& c_{j}=\frac{1}{1-n}\left(\frac{q_{j}}{P_{f}}\right)^{\frac{1}{\omega-1}} C_{f}
\end{aligned}
$$

Nesting the above functions we obtain

$$
\begin{aligned}
& c_{i}=\left(\frac{p_{i}}{P_{h}}\right)^{\frac{1}{\omega-1}}\left(\frac{P_{h}}{P}\right)^{\frac{1}{\theta-1}} C \\
& c_{j}=\left(\frac{q_{j}}{P_{f}}\right)^{\frac{1}{\omega-1}}\left(\frac{E P_{f}}{P}\right)^{\frac{1}{\theta-1}} C
\end{aligned}
$$

where $p_{i}$ is the price for the home produced good $i, q_{j}$ is the price for the foreign produced good $j$, whereas $P_{h}, P_{f}$ and $P$ are the price indexes of home produced final goods, foreign produced final goods purchased at home and the general home price index of consumption goods, namely

$$
\begin{aligned}
& P_{h}=\left(\frac{1}{n} \int_{0}^{n} p_{i}^{\frac{\omega}{\omega-1}} d i\right)^{\frac{\omega-1}{\omega}} \\
& P_{f}=\left(\frac{1}{1-n} \int_{n}^{1} q_{j}^{\frac{\omega}{\omega-1}} d j\right)^{\frac{\omega-1}{\omega}} \\
& P=\left(n P_{h}^{\frac{\theta}{\theta-1}}+(1-n) P_{f}^{\frac{\theta}{\theta-1}}\right)^{\frac{\theta-1}{\theta}}
\end{aligned}
$$

It is evident that the previous case of identical elasticities is just a particular case of this nested CES consumption index, i.e. where $\theta=\omega$. 
If we assume, as in the existing literature, that imperfect competition takes the form of monopolistic competition, ${ }^{16}$ the elasticity of demand faced by each producer is $\frac{1}{1-\omega}$.

Whereas the markup must still be positive, we might well have an elasticity of substitution between a domestic good and imported good smaller than one.

The importance of this specification is not at all exclusively theoretical. As reported in Krugman and Obstfeld (1997, p. 485) for most countries the elasticity of substitution in question is indeed smaller than one ${ }^{17}$.

\section{The Model}

We consider here the original Obstfeld and Rogoff (1995) model amended with the nested CES function described above.

Since the two countries are symmetric, here we show mainly the expressions for the Home country. Variables of the foreign country are those with an asterisk.

\section{Households}

There are $n$ households in the Home country and (1-n) in the foreign country. Within each country, households own equal shares of the firms. These households have identical preferences and, since there is no uncertainty, they choose consumption, real money balances and labour supply to solve the following problem

$$
\max _{C, \frac{M}{P}, l} \sum_{s=t}^{\infty} \beta^{t-s}\left[\frac{C_{s}^{1-\sigma}}{1-\sigma}+\frac{\chi}{1-\varepsilon}\left(\frac{M_{s}}{P_{s}}\right)^{1-\varepsilon}-\frac{l_{s}^{\mu}}{\mu}\right]
$$

\footnotetext{
${ }^{16}$ Goods are differentiated under physical characteristics and there is a large number of producers: one per good. This implies that the effects of each single producer on aggregate variables is negligible. (see Dixit and Stiglitz, 1977)

${ }^{17}$ The elasticity we are presenting here is the impact elasticity in the terminology of Krugman and Obstfeld. They show in fact that the elasticity changes overtime and indeed that the elasticity of imports and of exports do differ. According to Backus et al. (1994b), this elasticity of substitution is between 1 and 2 for U.S.A., and smaller for European countries. AGE models of trade provide various estimates of these elasticities, although typically for various industries rather than for aggregate measures of export and import. These estimates are also typically low. Shiells and Reinert (1993) for example report estimates for the elasticity of substitution between domestic and imported goods for 19 sectors (Shiells and Reinert, 1993, table 4). Only 4 sectors have an elasticity bigger than 1. Among these 4 the highest elasticity is 1.22. Recently Obstfeld and Rogoff (2000) have claimed that measures of the elasticity of substitution at hand are likely to be in the order of 6 . More research is clearly called upon to estimate these elasticities given the important implications both for trade policy analysis and for international macroeconomic theory.
} 


$$
\begin{aligned}
& \text { s.t. } M_{s}+P_{s} B_{s+1}=w_{s} l_{s}+\Pi_{s}+\left(1+v_{s}\right) P_{s} B_{s}+M_{s-1}-P_{s} C_{s}-\tau_{s} \\
& s=t \ldots \infty
\end{aligned}
$$

where all variables are in nominal terms except consumption, bonds and labour supply. $C$ is the consumption index defined in equation (2), $M$ is money, $B$ is a real bond, $P$ is the consumption price index as defined by equation (11), $w$ is the nominal wage, $l$ is labour, $\Pi$ is profit share, $\tau$ is tax paid by the individual and $v$ is the real interest rate. It is assumed that $\varepsilon, \sigma>0$ and $\mu>1$. Finally $\beta=(1+\delta)^{-1}, \delta$ (bounded between zero and one) is the rate of time preference.

From the first order condition of utility maximization the following functions are derived:

$$
\begin{aligned}
& \frac{M_{t}}{P_{t}}=C_{t}^{\frac{\sigma}{\varepsilon}}\left(\chi \frac{1+i_{t+1}}{i_{t+1}}\right)^{\frac{1}{\varepsilon}} \\
& l_{t}=\left(\frac{w_{t}}{P_{t}} C^{-\sigma}\right)^{\frac{1}{\mu-1}} \\
& C_{t+1}=\left[\beta\left(1+v_{t+1}\right)\right]^{\frac{1}{\sigma}} C_{t}
\end{aligned}
$$

which represent respectively, money demand, labour supply and the consumption Euler equation. $i$ denotes the nominal interest rate.

\section{Firms}

The production function has constant return to scale in labour and is identical across firms.

$$
y_{i}=\frac{1}{n} \int_{0}^{n} l_{i} d i=l
$$

Profit maximization in monopolistic competition implies that prices are set as a markup over marginal costs,

i.e.

$$
p=\frac{w}{\omega}
$$


We assume here that firms set prices for one period. That is to say that prices are fixed in the short run. We don't give any further explanations for this than those given in the related literature: mainly menu-costs arguments.

\section{Money supply}

Henceforth it is assumed that the following government's balanced budget holds:

$$
M_{t}-M_{t-1}+\tau=0
$$

In what follows we will consider only a permanent monetary shock, i.e. a permanent unexpected change in money supply.

\section{Current account dynamics}

To obtain the correlation between the exchange rate and the current account we simply follow Obstfeld and Rogoff (1996, ch. 10) and solve for differences between home and foreign loglinearized expressions.

Let us start with the consumption Euler equation. Since purchasing power parity (PPP) holds in this model, domestic and foreign real interest rate are identical so that we have

$$
\hat{C}_{t+1}-\hat{C}_{t+1}^{*}=\hat{C}_{t}-\hat{C}_{t}^{*}
$$

where $\hat{C}=d \log C$.

From the labour supply equation (15) and making use of the production function and the oligopoly pricing rule we obtain the output supply equation

$$
\hat{y}_{t}=\frac{1}{\mu-1}\left(\hat{p}_{t}-\hat{P}_{t}-\sigma \hat{C}_{t}\right)
$$

and the foreign counterpart

$$
\hat{y}_{t}^{*}=\frac{1}{\mu-1}\left(\hat{q}_{t}-\hat{P}_{t}^{*}-\sigma \hat{C}_{t}^{*}\right)
$$

where $\mathrm{q}$ is the price of a typical foreign good.

Taking the difference between the last two equations we obtain 


$$
\hat{y}_{t}-\hat{y}_{t}^{*}=\frac{1}{\mu-1}\left\{\hat{p}_{t}-\hat{q}_{t}-e_{t}-\sigma\left(\hat{C}_{t}-\hat{C}_{t}^{*}\right)\right\}
$$

which represents the difference in the (log-deviation) supply of goods, and where $e=d \log E$.

The corresponding difference in demand for goods is obtained by taking a weighted sum of equation (7) and the foreign counterpart (not shown) where weights are represented by the size of the population. Since $P=e P^{*}$ the demand for the $i-t h$ domestic good is

$$
y=c \equiv\left(\frac{p}{P}\right)^{\frac{1}{\theta-1}} C^{W}
$$

where $C^{W}=\left(n C+(1-n) C^{*}\right)$.

Consequently our log-linearized expression becomes

$$
\hat{y}_{t}-\hat{y}_{t}^{*}=\frac{1}{\theta-1}\left(\hat{p}_{t}-\hat{q}_{t}-e_{t}\right)
$$

Market clearing requires equation (22) and (23) to be equal, which yields

$$
\hat{p}_{t}-\hat{q}_{t}-e_{t}=\frac{1-\theta}{\mu-\theta} \sigma\left(\hat{C}_{t}-\hat{C}_{t}^{*}\right)
$$

Notice that the left hand side of the last equation represents the log-deviation of the terms of trade from the initial steady state.

As for the budget constraint, applying the following identity $w_{t} l_{t}+\Pi_{t} \equiv p y_{t}$ together with the market clearing condition we obtain

$$
b_{t+1}=(1+\delta) b_{t}+\frac{\theta}{\theta-1}\left(\hat{p}_{t}-\hat{P}_{t}\right)+\hat{C}_{t}^{W}-\hat{C}_{t}
$$

and the foreign counterpart

$$
b_{t+1}^{*}=(1+\delta) b_{t}^{*}+\frac{\theta}{\theta-1}\left(\hat{q}_{t}-\hat{P}_{t}^{*}\right)+\hat{C}_{t}^{W}-\hat{C}_{t}^{*}
$$


where $b=\frac{B}{C_{s s}}$. Since the initial steady state bond holding, $B_{s s}$, is zero we use steady state consumption as the unit of measure for the change in bonds holdings.

Once it is noted that $b^{*}=-\frac{n}{1-n} b$, we can subtract the foreign budget constraint from the home one to obtain

$$
\frac{1}{1-n} b_{t+1}=\frac{1+\delta}{1-n} b_{t}+\frac{\theta}{\theta-1}\left(\hat{p}_{t}-\hat{q}_{t}-e_{t}\right)-\left(\hat{C}_{t}-\hat{C}_{t}^{*}\right)
$$

Finally from money demand we get

$$
m_{t}-\hat{P}_{t}=\frac{\sigma}{\varepsilon} \hat{C}_{t}-\frac{1}{\varepsilon}\left(\frac{\hat{P}_{t+1}-\hat{P}_{t}}{\delta}+\frac{\hat{v}_{t+1}}{1+\delta}\right)
$$

where $m=d \log M$ and for which we have made use of the Fisher equation. ${ }^{18}$

Subtracting the foreign counterpart (not shown) from (28), we obtain

$$
m_{t}-m_{t}^{*}=e_{t}+\frac{\sigma}{\varepsilon}\left(\hat{C}_{t}-\hat{C}_{t}^{*}\right)-\frac{1}{\varepsilon}\left(\frac{e_{t+1}-e_{t}}{\delta}\right)
$$

As shown by Obstfeld and Rogoff (1996, ch. 10), with PPP holding through time, there is no overshooting of the exchange rate, ${ }^{19}$ so that the last term in the last equation disappears, implying

$$
m_{t}-m_{t}^{*}=e_{t}+\frac{\sigma}{\varepsilon}\left(\hat{C}_{t}-\hat{C}_{t}^{*}\right)
$$

\section{Long run solution: flexible prices}

Since prices are fixed only for one period, the long run coincides with period $t+1$. We can thus reconsider all our previous relations starting with the budget constraint. Since the only change in bond holdings derives from the short run shock, i.e. $b_{t+2}=b_{t+1}$, leading equation (27) by one period, we get

${ }^{18}$ i.e. $\frac{\delta}{1+\delta} \hat{i}_{t+1}=\frac{\delta}{1+\delta} \hat{v}_{t+1}+\hat{P}_{t+1}-\hat{P}_{t}$

${ }^{19}$ This could be easily shown with our equation by resorting to the permanency of the monetary shock so that $m_{t+1}-m_{t+1}^{*}=m_{t}-m_{t}^{*}$ 


$$
\frac{\delta}{1-n} b_{t+1}=\frac{\theta}{1-\theta}\left(\hat{p}_{t+1}-\hat{q}_{t+1}-e_{t+1}\right)+\left(\hat{C}_{t+1}-\hat{C}_{t+1}^{*}\right)
$$

which by equation (24) reduces to

$$
\left[\left(\frac{\mu-\theta}{\theta(\sigma-1)+\mu}\right)\left(\frac{\delta}{1-n}\right)\right] b_{t+1}=\left(\hat{C}_{t+1}-\hat{C}_{t+1}^{*}\right)
$$

or

$$
\left(\frac{(1-\theta) \sigma}{\theta(\sigma-1)+\mu}\right)\left(\frac{\delta}{1-n}\right) b_{t+1}=\left(\hat{p}_{t+1}-\hat{q}_{t+1}-e_{t+1}\right)
$$

As noted by Obstfeld and Rogoff (1996, p.672), equation (30) describes the wealth effect on consumption differentials.

\section{The transfer problem}

This last relation shows already the effects of our specification of the elasticities as compared with the results obtained by the original specification. At least in theory, it is possible to obtain a negative correlation between the terms of trade $(\hat{p}-\hat{q}-e)$ and the current account: just set $\theta<0$ and $\sigma>1-\frac{\mu}{\theta}$. In Obstfeld and Rogoff (1996, ch. 10) the positive correlation between the current account and the terms of trade is interpreted as confirming the argument of Keynes (1929) in support of the "transfer problem". Our finding shows that the conclusion drawn by Obstfeld and Rogoff is due to their restrictive assumptions on elasticities.

\section{Short run sticky prices}

To derive the short run responses to a monetary shock we just need to take account of the fact that $\hat{p}_{t}=\hat{q}_{t}=0$ since prices can not deviate from the initial steady state level in the short run.

Let us then start with the budget constraint. Equation (27) reduces now to

$$
\frac{1}{1-n} b_{t+1}=-\frac{\theta}{\theta-1} e_{t}-\left(\hat{C}_{t}-\hat{C}_{t}^{*}\right)
$$


Note that the change in bond holdings takes place exclusively in the short run and is permanent. In the long run prices adjust to clear the market and the current account returns to balance. Note also that $b_{t}=0$ since it is the "state variable" of the system: it refers to bonds accumulated before the shock.

Equation (30) and (32) must be both true so that using equation (19) we obtain

$$
\left(\hat{C}_{t}-\hat{C}_{t}^{*}\right)=\Delta e_{t}
$$

where

$$
\Delta=\frac{\theta}{1-\theta}\left[\frac{(\mu-\theta) \delta}{(\mu-\theta)(1+\delta)+\theta \sigma}\right]
$$

We can now rearrange the monetary shock equation (29) using equation (33) to get

$$
e_{t}=\left(\frac{\varepsilon}{\varepsilon+\sigma \Delta}\right)\left(m_{t}-m_{t}^{*}\right)
$$

Finally using equation (32), (33) and (34) we find the correlation between money shocks and the trade balance/current account, namely

$$
\frac{1}{1-n} b_{t}=\widetilde{\Omega}\left(m_{t}-m_{t}^{*}\right)
$$

where

$$
\widetilde{\Omega}=\frac{\theta \varepsilon[(\mu-\theta)+\theta \sigma]}{\varepsilon(1-\theta)[(\mu-\theta)(1+\delta)+\theta \sigma]+\sigma \theta \delta(\mu-\theta)}
$$

\section{Trade balance response}

\section{Graphical analysis}

Let us rewrite equation (30) as

$$
\frac{1}{1-n} b_{t+1} \equiv C A_{L}=\Omega\left(\hat{C}_{t}-\hat{C}_{t}^{*}\right)
$$


where $\Omega=\left(\frac{\theta(\sigma-1)+\mu}{\delta(\mu-\theta)}\right)$, and equation (32) as

$$
\frac{1}{1-n} b_{t+1} \equiv C A_{S}=-\frac{\theta}{\theta-1} e_{t}-\left(\hat{C}_{t}-\hat{C}_{t}^{*}\right)
$$

The actual response of the current account is given by the intersection of these two lines, i.e. when $C A_{L}=C A_{S}$.

Figure (1) shows the "typical" case, where $\theta<0$ implies that an exchange rate depreciation improves the current account.

$$
\text { [figure(1)here] }
$$

Figure (2) shows current account response when $\theta<0$ and $\Omega>0$. In this case a depreciation of the domestic currency is associated with a deterioration of the current account and with a negative consumption differential.

$$
\text { [figure(2)here] }
$$

Figure (3) shows a deterioration of the current account associated with $\Omega<-1$. The consumption differential is positive.

$$
\text { [figure(3)here] }
$$

Finally, figure (4) shows the case in which $\Omega<0$ and in module smaller than one. The current account improves contrary to what one would expect having $\theta<0$. This improvement is associated with a negative consumption differential.

$$
\text { [figure(4)here] }
$$


To understand which of these cases is more likely to occur given plausible values for the parameters, requires a closer study of the analytical solution. The following section shows that the last of these four cases is not very likely to occur.

\section{The Marshall-Lerner condition: II}

We are now able to determine the ML condition that apply to the OR model, as described in the preceding sections.

Let us rewrite the trade balance using our functional forms

$$
T B=\frac{P_{h}}{P}\left(\frac{P_{h}}{P}\right)^{\frac{1}{\theta-1}} C^{*}-\frac{E P_{f}}{P^{*}}\left(\frac{E P_{f}}{P^{*}}\right)^{\frac{1}{\theta-1}} C
$$

We can distinguish the substitution effect from the income effect induced by a currency depreciation.

The substitution effect is simply $(1-n) \frac{1}{\theta-1}$ for export and $n \frac{1}{\theta-1}$ for import $^{20}$.

The income effect is given by

$$
\frac{d \log C^{*}}{d \log E}-\frac{d \log C}{d \log E}=\frac{\hat{C}^{*}-\hat{C}}{e}=-\Delta
$$

where we have made use of equation (33).

Therefore the $T B$ improves, for a given depreciation of the exchange rate, if $^{21}$

$$
\begin{aligned}
& \varepsilon_{E X}+\left|\varepsilon_{I M}\right|-1>0 \Leftrightarrow\left(\frac{\theta}{\theta-1}\right)-\Delta>0 \\
& \text { i.e. }\left(\frac{\theta}{\theta-1}\right)[1-\widetilde{\Delta}]>0
\end{aligned}
$$

where $\widetilde{\Delta}=\frac{1-\theta}{\theta} \Delta$.

The sign of the first term of expression (37) depends on the elasticity of substitution being bigger or smaller than one, i.e.

\footnotetext{
${ }^{20}$ Note that we have made use of equation (11).

${ }^{21}$ This condition can be obtained also by substituting equation (33) in equation (32).
} 


$$
\frac{\theta}{1-\theta}>0 \text { iff } \frac{1}{1-\theta}>1
$$

Therefore the demand elasticity of substitution between imported and domestically produced goods makes only for the "substitution effect" of the ML condition ${ }^{22}$.

Is the demand elasticity of substitution between imported and domestically produced goods sufficient to determine the response of the $T B$ in the OR basic model?

The answer to this question is "yes" for practical purposes. To see why, let us consider the term $1-\widetilde{\Delta}$, i.e.

$$
1-\widetilde{\Delta} \equiv \frac{(\mu-\theta)+\theta \sigma}{(\mu-\theta)(1+\delta)+\theta \sigma}
$$

With regard to the sign of $1-\widetilde{\Delta}$ we can easily distinguish two cases

1. $\theta>0\left(\frac{1}{1-\theta}>1\right):$ since $\mu>1$ we have that $1-\widetilde{\Delta}>0$. That is, the ML condition is satisfied as long as $\frac{1}{1-\theta}>1$.

2. $\theta<0\left(\frac{1}{1-\theta}<1\right):$ In this case it might well be that $1-\widetilde{\Delta}<0$ so that looking only at the elasticity of substitution would not be sufficient to determine the sign of the trade balance response. Yet, it is obvious that the numerator and the denominator of expression (38) change sign "almost" simultaneously. More precisely $1-\widetilde{\Delta}$ has a singularity point in $\theta=-\frac{\mu}{\sigma-(1+\delta)}$, in which the denominator changes sign. As for the numerator, it changes sign in $\theta=-\frac{\mu}{\sigma-1}$. Hence numerator and denominator have the same sign $(1-\widetilde{\Delta}>0)$ except for a small interval of $\theta$. The dimension of this interval is of order $\delta .^{23}$

\footnotetext{
${ }^{22}$ Devereux (1999) refers to this elasticity only in relation to the ML condition.

${ }^{23}$ Note that the discontinuity, if exists, lies to the left of the point in which the $T B$ response changes sign.
} 
We can therefore conclude that for practical purposes the response of the trade balance to a currency depreciation in the basic OR model is governed by the elasticity of substitution between domestic and imported goods.

A possible intuition about some of the forces at play, can be gained by considering a particular case. For $\sigma \in(1,1+\delta)$, the trade balance response to a currency depreciation switches to positive at about $\theta=-1$ and stays positive for all $\theta$ smaller than that value. In this very particular case one can say that the ML conditions are independent of the elasticity of substitution between domestic and imported goods. For this to be possible two conditions must hold. 1) the substitution effect on the intertemporal allocation of consumption, must be smaller than the income effect (the intertemporal elasticity of substitution $<1$ ). 2) the consumer must prefer current consumption to future consumption less than she prefers a smoother consumption path $\left(\frac{1}{\sigma}>\frac{1}{1+\delta}\right)$. Under these conditions, when the "expenditure switching" becomes too weak, the income effects prevails in such a way that the $T B$ improves. An example is shown in figure (5) ${ }^{24}$

\section{[figure(5)here]}

When only the first condition holds, a singularity point emerges at which the $T B$ response changes sign once more. By its nature, this fact cannot easily be explained. We refrain from trying to find a rationale. Yet, it is clear that when $\frac{1}{\sigma}<\frac{1}{1+\delta}$, the future stream of wealth stemming from the CA surplus is valued more than the smoothing of consumption is. There is then a degree of substitutability under which the big CA surplus triggers disproportionate domestic consumption, so that the surplus is not sustainable anymore ${ }^{25}$.

To see the role of the parameter $\mu$ (determining the elasticity of labour supply), it is convenient to consider the case in which the two conditions above are satisfied ${ }^{26}$. The smaller is $\mu$

\footnotetext{
${ }^{24}$ The figure shows an unrealistic case since $\delta=0.9$. We impose this value only for the sake of the example. The smaller is $\delta$ the more leftward is the intersection with the negative horizontal axis, keeping $\sigma \in(1,1+\delta)$

${ }^{25}$ This is a description rather than an explanation of what happens in the singularity point. The problem in deriving a clear explanation is that the parameter $\theta$ determines both the substitution effect and the income effect of the ML condition, and these two effects work in the opposite direction in the case at hand.

${ }^{26}$ This because the parameter $\mu$ does not affect the interval of $\theta$ in which the $T B$ changes sign.
} 
the more elastic is the labour supply and the bigger is the complementarity between consumption and leisure. The degree of expenditure switching $(\theta)$ determines the international division of labour. With a small value for $\mu$ (high complementarity between consumption and leisure), consumption should not increase too much to match the reduced leisure ${ }^{27}$. For a given $\theta$, a small enough $\mu$ will keep consumption at a level such that the trade balance improves.

The difficulty to interpret the change in sign in the $T B$ response for small enough $\theta$, derives from the interaction between consumption differentials $\left(\hat{C}-\hat{C}^{*}\right)$ and the CA. On one side we have the wealth effect from the CA to the consumption differentials (the CA wealth effect): this is positive for $\theta>-\frac{\mu}{\sigma-1}$. On the other side we have the effect from the consumption differential to the CA: the income effect of the ML conditions. This is always positive (i.e. unitary) in this model. Analogously we have a similar interaction between the exchange rate and the CA. On one side the CA affects the exchange rate through its wealth effect on labour supply and relative prices. On the other hand the exchange rate affects the CA through the substitution effect of the ML conditions. The parameters $\theta, \mu, \delta$ and $\sigma$ all affects these 4 effects in a complex way.

\section{Current account and monetary shocks}

An important issue addressed by the OR class of models is the response of real variables to monetary shocks. One of the crucial variables of interest in this study is the current account. Current account and trade balance are synonymous when we consider, qualitatively, the impact effect of a perturbation around the symmetric equilibrium. Therefore, the relationship between the trade balance and the exchange rate developed in the previous section does still apply to the current account/exchange rate relation.

To establish the response of the current account to a monetary shock we need to determine the response of the exchange rate to a monetary shock. This relationship is defined by equation (34), i.e.

$$
\frac{e}{m-m^{*}}=\frac{\varepsilon}{\varepsilon+\sigma \Delta}
$$

\footnotetext{
${ }^{27}$ Output is demand determined and it is produced with labour only.
} 
We refer the reader to the appendix of this paper for a detailed analysis of the current account/monetary shock relationship. Here we just note that for practical purposes, as long as one is willing to assume a positive relationship between the exchange rate and the money supply, a positive domestic monetary shock will improve the current account if the ML conditions are satisfied.

\section{Conclusions}

In this paper we have shown that in the Obstfeld and Rogoff class of models appropriately amended, the Marshall-Lerner (ML) condition does still govern the response of the current account to relative price changes. We have also shown that the mere elasticity of substitution between domestic and imported goods is a good approximation to the ML condition in this particular setting. That is, the CA generally deteriorates, consequent upon a currency depreciation, if the domestic and imported goods are poor substitutes.

This paper has also shown that disentangling the markup from the elasticity of substitution between domestic and imported goods, opens the way to a wider range of responses of the current account and terms of trade to monetary shocks in the Obstfeld and Rogoff class of models. This clearly improves the ability of this class of models to fit the empirical evidence.

The intertemporal structure of this model affects also the elasticity of the current account to monetary shocks. Whether this intertemporal effect is marginal or not in the present model, depends on the values of the parameters. A more complex model, e.g. with capital accumulation, staggered price adjustments, pricing to market etc. will certainly affect the balance between the various determinants of the current account response to monetary shocks. Our paper has shown that these determinants can broadly be classified as the substitution effect and the (dynamic) income effect, as in the traditional open-economy models.

\section{Appendix}

The problem of solving for the sign of the current account response to a monetary shock reduces to the following

$$
\operatorname{sign}\left(\frac{d b}{d\left(m-m^{*}\right)}\right)=\operatorname{sign}(\widetilde{\Omega})
$$

Let us give the following definition 
Definition $1 \theta^{*}$ is the root of $\widetilde{\Omega}$, i.e. $\widetilde{\Omega}\left(\theta^{*}\right)=0$; if a second root exists ${ }^{28}$, it is $\theta^{* *}=\frac{-\mu}{\sigma-1}$, i.e. $\widetilde{\Omega}\left(\theta^{* *}\right)=0$. Let us also denote with $\hat{\theta}$ the value of $\theta$ such that denominator $(\widetilde{\Omega}(\hat{\theta}))=0$, i.e. the singularity point of $\widetilde{\Omega}$ in terms of $\theta^{29}$.

Then we can state the following proposition that holds for all plausible cases ${ }^{30}$

\section{Proposition 1:}

$$
\begin{aligned}
& \text { 1. if } \varepsilon>\mu \text { or } \varepsilon<\mu \text { and } \sigma<\frac{\mu-1}{\frac{\mu}{\varepsilon}-1} \text { then } \\
& \widetilde{\Omega}>0 \text { iff } \theta \in(0,1] \text { or } \theta \in\left(\hat{\theta}, \theta^{* *}\right) \\
& \widetilde{\Omega}<0 \text { iff } \theta \in(-\infty, \hat{\theta}) \operatorname{or} \theta \in\left(\theta^{* *}, 0\right) \\
& \text { 2. if } \mu>\varepsilon \text { and } \sigma>\frac{\mu-1}{\frac{\mu}{\varepsilon}-1} \text { then } \\
& \widetilde{\Omega}>0 \text { iff } \theta \in(0,1) \text { or } \theta \in\left(\theta^{* *}, \hat{\theta}\right) \\
& \widetilde{\Omega}<0 \text { iff } \theta \in\left(-\infty, \theta^{* *}\right) \text { or } \theta \in(\hat{\theta}, 0)
\end{aligned}
$$

3. If $\theta^{* *}=\hat{\theta}$ then $\widetilde{\Omega}<0$ iff $\theta<0$.

The proof is given below.

This proposition includes the case analysed in Obstfeld and Rogoff $(1995,1996)$ where the elasticity of intra-temporal substitution is bigger than one and where there is a positive correlation

\footnotetext{
${ }^{28}$ This second root does not exist if $\sigma=\varepsilon(\mu-1) /(\mu-\varepsilon)$. In this case the discontinuity and the root coincide, yielding a negative value of $\widetilde{\Omega}$.

${ }^{29}$ In the appendix it is proved that of the two discontinuity points only one lies within the admissible range. $\hat{\theta}$ refers clearly to the admissible value.

${ }^{30}$ if $\sigma \in\left(1,(1+\delta) /\left(1+\frac{\delta}{\varepsilon}\right)\right)$, then $\widetilde{\Omega}<0$ for all plausible negative $\theta$.
} 
between money and the current account. But it also shows that there are plausible values of the parameters for which the current account deteriorates after a positive monetary shock. A graphical example will show this point, which is the central result of this paper.

Let us assume the following values for the relevant parameters: $\mu=1.5, \sigma=2, \varepsilon=9, \delta=0.05$. The relation between the response of the trade balance to a monetary shock and $\theta$ is shown in figure 6 . On the right side of the vertical axis we have the Obstfeld and Rogoff (1995) case: an elasticity of substitution bigger than one implies a positive response of the trade balance. The origin of the axes coincide with the formulation of Corsetti and Pesenti (1997). Finally, the left side of the vertical axis shows that an elasticity of substitution smaller than one $(\theta<0)$ can easily produce a negative response of the trade balance.

\section{[figure (6) here]}

\section{Proof of Proposition 1}

Proof. Let us start by recalling the following expression

$$
\widetilde{\Omega}=\frac{\theta \varepsilon[(\mu-\theta)+\theta \sigma]}{\varepsilon(1-\theta)[(\mu-\theta)(1+\delta)+\theta \sigma]+\sigma \theta \delta(\mu-\theta)}
$$

$\widetilde{\Omega}$ is thus a rational function of our 5 parameters, which have the following admissible ranges:

$$
\theta \in(-\infty, 1) ; \varepsilon \in(1, \infty) ; \sigma \in(0, \infty) ; \mu \in(1, \infty) ; \delta \in(0,1)
$$

Since we are mainly interested in the dynamics of the trade balance in relation to the intratemporal elasticity of substitution, the two key parameters are $\theta$ and $\sigma$ (the inverse of the intertemporal elasticity of substitution). For convenience we will then study $\widetilde{\Omega}$ as a function of $\theta$, the critical values of which will be considered at varying $\sigma$.

As for the first point of Proposition 1, it is self-evident that for $\theta \in(0,1), \widetilde{\Omega}$ is positive. 
Note then that the numerator of $\widetilde{\Omega}$, is a second degree polynomial in $\theta$. The two roots can be easily derived as $\theta^{*}=0$ and $\theta^{* *}=\frac{-\mu}{\sigma-1}$. Clearly $\theta^{* *}$ exists only for $\sigma>1$.

The denominator of $\widetilde{\Omega}, \widetilde{\Omega}_{D}$, is also a second degree polynomial in $\theta$. Unfortunately the two roots of $\widetilde{\Omega}_{D}$ are too cumbersome to be used to derive any conclusion about the dynamics. Nevertheless, we can easily rule out one of the roots of $\widetilde{\Omega}_{D}$ by resorting to the upper bound of the range of $\theta$ together with the fact that $\left.\widetilde{\Omega}(\theta)\right|_{\theta \in(0,1)}>0$.

To see this, let us write the roots of $\widetilde{\Omega}_{D}$ as

$$
x_{1,2}=\left(-\frac{b}{2 a}\right) \pm \sqrt{\left(-\frac{b}{2 a}\right)-\frac{c}{a}}
$$

where

$$
\begin{aligned}
& a=\sigma(\delta+\varepsilon)-\varepsilon(\delta+1) \\
& b=-\sigma(\delta \mu+\varepsilon)+\varepsilon(\mu+1)(\delta+1) \\
& c=-\varepsilon \mu(\delta+1)
\end{aligned}
$$

so that

$$
\begin{aligned}
& a>0 \text { iff } \sigma>\frac{1+\delta}{1+\delta / \varepsilon} \equiv \sigma_{1} \\
& -b>0 \text { iff } \sigma>\frac{\varepsilon(\mu+1)(1+\delta)}{\varepsilon+\delta \mu} \equiv \sigma_{2} \\
& c<0 \text { always }
\end{aligned}
$$

Moreover $\sigma_{2}>\sigma_{1}$, so that $-\frac{b}{2 a}<0$ iff $\sigma_{1}<\sigma<\sigma_{2}$.

Then, one can easily see that

$$
\begin{aligned}
& \frac{b}{2 a}>0 \Rightarrow x_{1}>0 \text { iff }-\frac{c}{a}>0 \\
& \frac{b}{2 a}<0 \Rightarrow x_{1}>0 \text { always }
\end{aligned}
$$

and 


$$
\begin{aligned}
& -\frac{b}{2 a}>0 \Rightarrow x_{2}>0 \text { iff }-\frac{c}{a}<0 \\
& -\frac{b}{2 a}<0 \Rightarrow x_{2}>0 \text { never }
\end{aligned}
$$

which in turn implies

- $\quad \hat{\theta}_{1}>0$ is always true, since by equations (39) $\hat{\theta}_{1}<0$ iff $a<0$ and $b<0$, i.e. iff $\sigma<\sigma_{1}$ and $\sigma>\sigma_{2}$ (by equations (41)), which is not possible. In this case one can verify that $\hat{\theta}_{1}>1$, which lies outside the admissible range.

- $\hat{\theta}_{2}<0$ iff $\sigma>\sigma_{1}$ since, by equations (40) and (41) $\hat{\theta}_{2}>0$ if $a<0$ and $b>0$, i.e. iff $\sigma<\sigma_{1}$ and $\sigma<\sigma_{2}$. Again, In this case one can verify that $\hat{\theta}_{2}>1$, which lies outside the admissible range.

Since $\sigma_{1}>1$ we can say that except for the narrow interval $\sigma \in\left(1, \sigma_{1}\right), \hat{\theta}_{2}<0$ exists only if $\theta^{* *}$ exists (i.e. $\left.\sigma>1\right)$. Furthermore for $\sigma \in\left(1, \sigma_{1}\right)$ we have that $\theta^{* *}$ is implausibly big in absolute terms, so that for all plausible negative values of $\theta$ we have $\widetilde{\Omega}<0$.

It can be verified that $\theta^{* *}=\hat{\theta}_{2}$ occurs only for $\sigma=\frac{\varepsilon(\mu-1)}{\mu-\varepsilon} \equiv \hat{\sigma}^{* *}$, which in turn exists only if $\mu>\varepsilon .{ }^{31}$ In this particular case it can be shown that

$$
\left.\lim _{\theta \rightarrow \theta^{* *}} \widetilde{\Omega}\right|_{\sigma=\hat{\sigma}^{* *}}=-\frac{\mu}{(\mu-1)+\sigma(\delta+1)}<0
$$

The last result together with the fact that ${ }^{32} \hat{\theta}_{1} \neq \hat{\theta}_{2}$ implies in turn that $\widetilde{\Omega}$ changes sign in $\hat{\theta}$ as long as $\hat{\theta} \neq \theta^{* *}$. Although we cannot say a priory the direction of sign change for $\hat{\theta}$ we can resort to the following result:

$$
\left.\frac{\partial \tilde{\Omega}}{\partial \theta}\right|_{\theta=\theta^{* *}}=-\frac{\varepsilon(\sigma-1)^{2}}{\delta \sigma(\sigma(\varepsilon-\mu)+\varepsilon(\mu-1))}>0 \text { iff } \mu>\varepsilon \text { and } \sigma>\hat{\sigma}^{* *}
$$

\footnotetext{
${ }^{31}$ The literature is not unanimous on the size of the elasticity of money demand $(1 / \varepsilon)$. Sutherland (1996) borrows a value of $\varepsilon=9$ from the literature cited therein. Betts and Devereux (1996) use a unitary elasticity of money demand. The latter case seems rather exceptional and more plausible for a long run money demand.

${ }^{32}$ This can be easily verified noting that $b^{2}-4 a c \neq 0$.
} 
This leads us to conclude that, if $\mu>\varepsilon$ then

- $\quad$ if $\sigma<\hat{\sigma}^{* *}$, then case 1) of Proposition 1 applies, otherwise case 2) applies.

\section{References}

Backus, D., Kehoe, P., and Kydland, F. (1994a). Dynamics of the Trade Balance and Terms of Trade: The J-Curve? American Economic Review, 84:84-103.

Backus, D., Kehoe, P., and Kydland, F. (1994b). Relative Price Movements in Dynamic General Equilibrium Models of International Trade. In Van der Ploeg, F., editor, Handbook of International Macroeconomics, chapter 3, pages 62-96. Basil Blackwell.

Baxter, M. and Crucini, M. J. (1993). Explaining Saving-Investment Correlations. American Economic Review, 83:416-436.

Betts, C. and Devereux, M. B. (1996). The Exchange Rate in a Model of Pricing-to-Market. European Economic Review, 40:1007-1021.

Bloningen, B. A. and Wilson, W. W. (1999). Explaning Armington: What Determines Substitutability Between Home and Foreign Goods. Canadian Journal of Economics, 32:1-21.

Chari, V., Kehoe, P. J., and McGrattan, E. R. (1997). Monetary Shocks and Real Exchange Rates in Sticky Price Models of International Business Cycle. NBER working paper (5876).

Chari, V., Kehoe, P. J., and McGrattan, E. R. (1998). Monetary Shocks and Real Exchange Rates in Sticky Price Models of International Business Cycle. Federal Reserve Bank of Minneapolis, Research Department Staff Report, 223.

Corsetti, G. and Pesenti, P. (1997). Welfare and Macroeconomic Interdependence. NBER working paper (6307). 
Danthine, J. P. and Donaldson, J. B. (1993). Methodological and Empirical Issues in Real Business Cycle Theory. European Economic Review, 37:1-35.

de Melo, J. and Robinson, S. (1989). Product Differentiation and the Treatment of Foreign Trade in Computable General Equilibrium Models of Small Economies. Journal of International Economics, 27:47-67.

Devereux, M. B. (1999) How Does a Devaluation Affect the Current Account?, Department of Economics, UBC.

Dixit, A. K. and Stiglitz, J. E. (1977). Monopolistic Competition and Optimum Product Diversity. American Economic Review, 67:297-308.

Ethier, W. J. (1988). Modern International Economics. W.W. Norton, second edition.

Francois, J. F. and Shiells, C. R. (1994). AGE Models of North American Free Trade. In Francois, J. F. and Shiells, C. R., editors, Modelling Trade Policy, chapter 1, pages 3-44. Cambridge University Press, Cambridge.

Keynes, J. M. (1929) The German Transfer Problem. Economic Journal, 39:1-7.

Kollmann, R. (1997). “The Exchange Rate in a Dynamic-Optimising Current Account Model with Nominal Rigidities: A Quantitative Investigation”. IMF working paper.

Krugman, P. and Obstfeld, M. (1997). International Economics: Theory and Policy. Addison-Wesley, $4^{\text {th }}$ edition.

Lane, P. (1999a). "Money Shocks and the Current Account”. In G. Calvo, R. D. and Obstfeld, M., editors, Money, Factor Mobility and Trade: Essays in Honor of Robert Mundell. MIT Press, Cambridge, MA. 
Lane, P. (1999b). “The New Open Economy Macroeconomics: A Survey”. CEPR Discussion Paper 2115.

Mendoza, E. G. (1995). The Terms of Trade, the Real Exchange Rate and Economic Fluctuations. International Economic Review, 36-101-137.

Obstfeld, M. (1982). "Aggregate Spending and the Terms of Trade: Is there a LaursenMetzler Effect?”. Quarterly Journal of Economics, 97:251-270.

Obstfeld, M. and Rogoff, K. (1995). "Exchange Rate Dynamics Redux”. Journal of Political Economy, 103:624-660

Obstfeld, M. and Rogoff, K. (1996). Foundations of International Macroeconomics, MIT Press, Cambridge, MA.

Obstfeld, M. and Rogoff, K. (1998). "Risk and Exchange Rage”. NBER working paper (6694).

Obstfeld, M. and Rogoff, K. (2000). "The Six Major Puzzles in International Macroeconomics: Is There a Common Cause?”. NBER working paper (7777).

Shiells, C. R. and Reinert, K. A. (1993). “Armington Models and Terms-of-Trade Effects: Some Econometric Evidence for North America". Canadian Journal of Economics, 26:299-316.

Sutherland, A. (1996). "Financial Market Integration and Macroeconomic Volatility". Scandinavian Journal of Economics, 98:521-541.

Tille, C. (1999). "The Role of Consumption Substitutability in the International Transmission of Shocks". Federal Reserve Bank of New York, mimeo 
Trefler, D. (1995). "The Cause of Missing Trade and Other Mysteries". American Economic Review, 85:1029-1046 


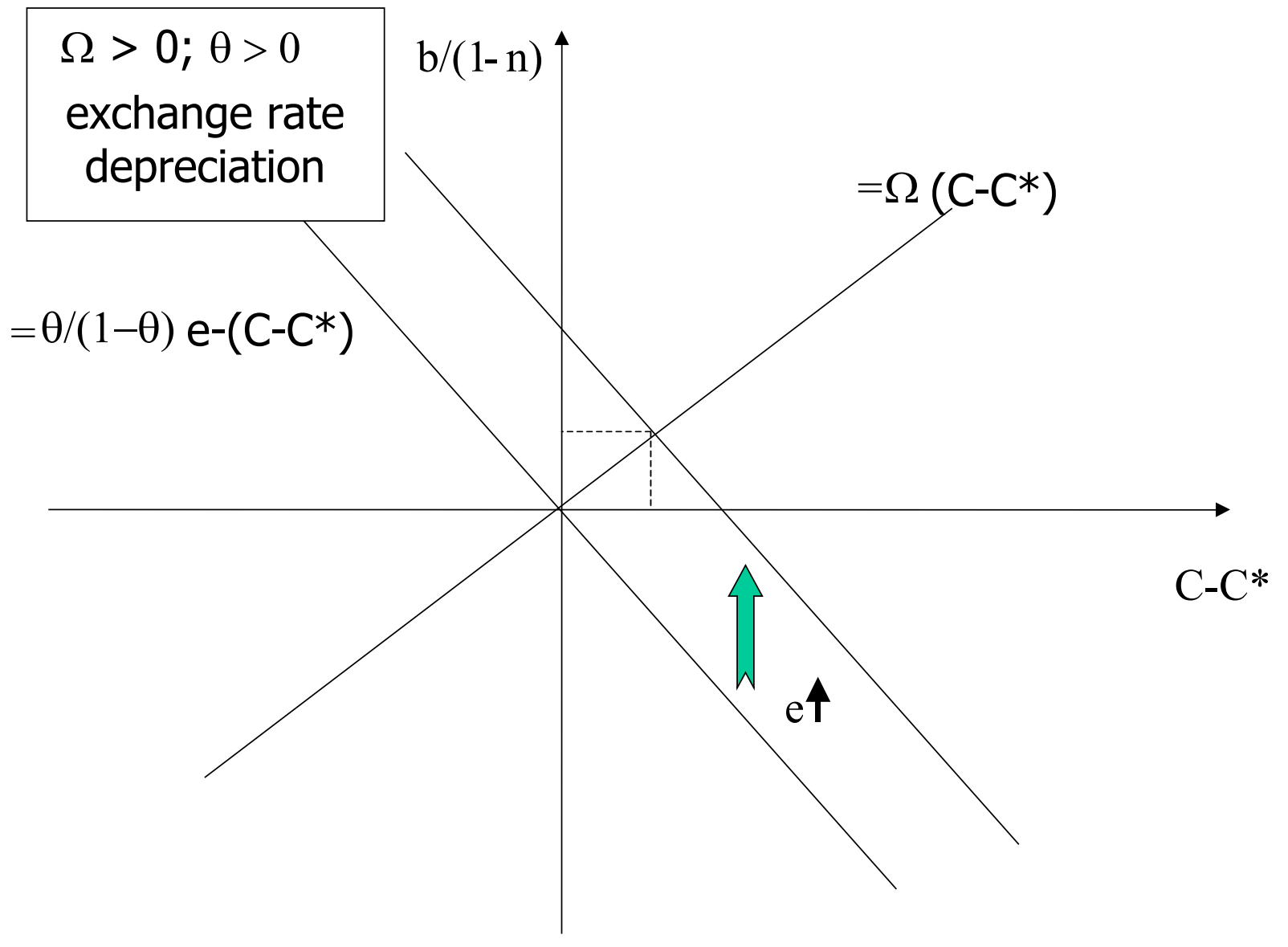

Figure 1 


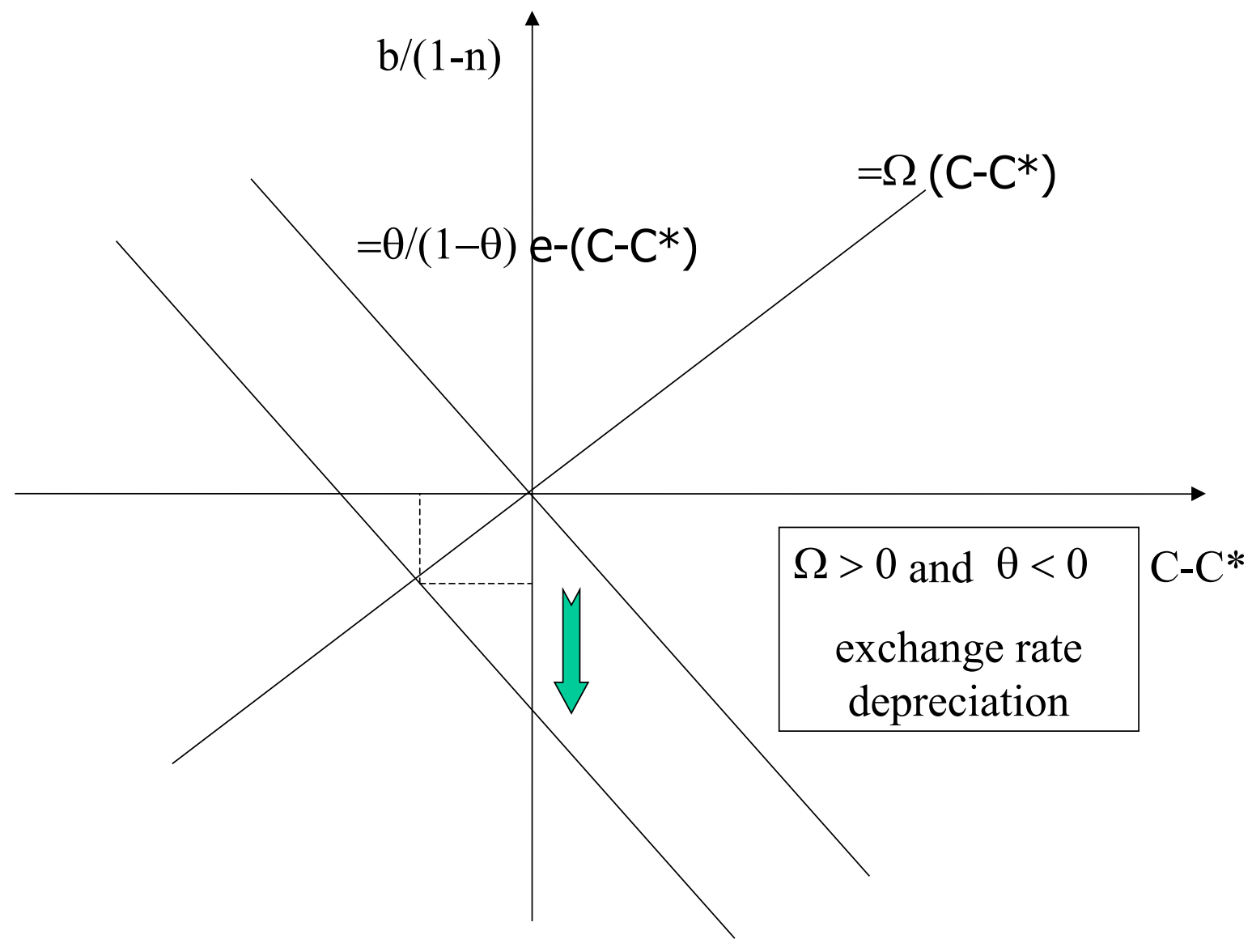

Figure 2 


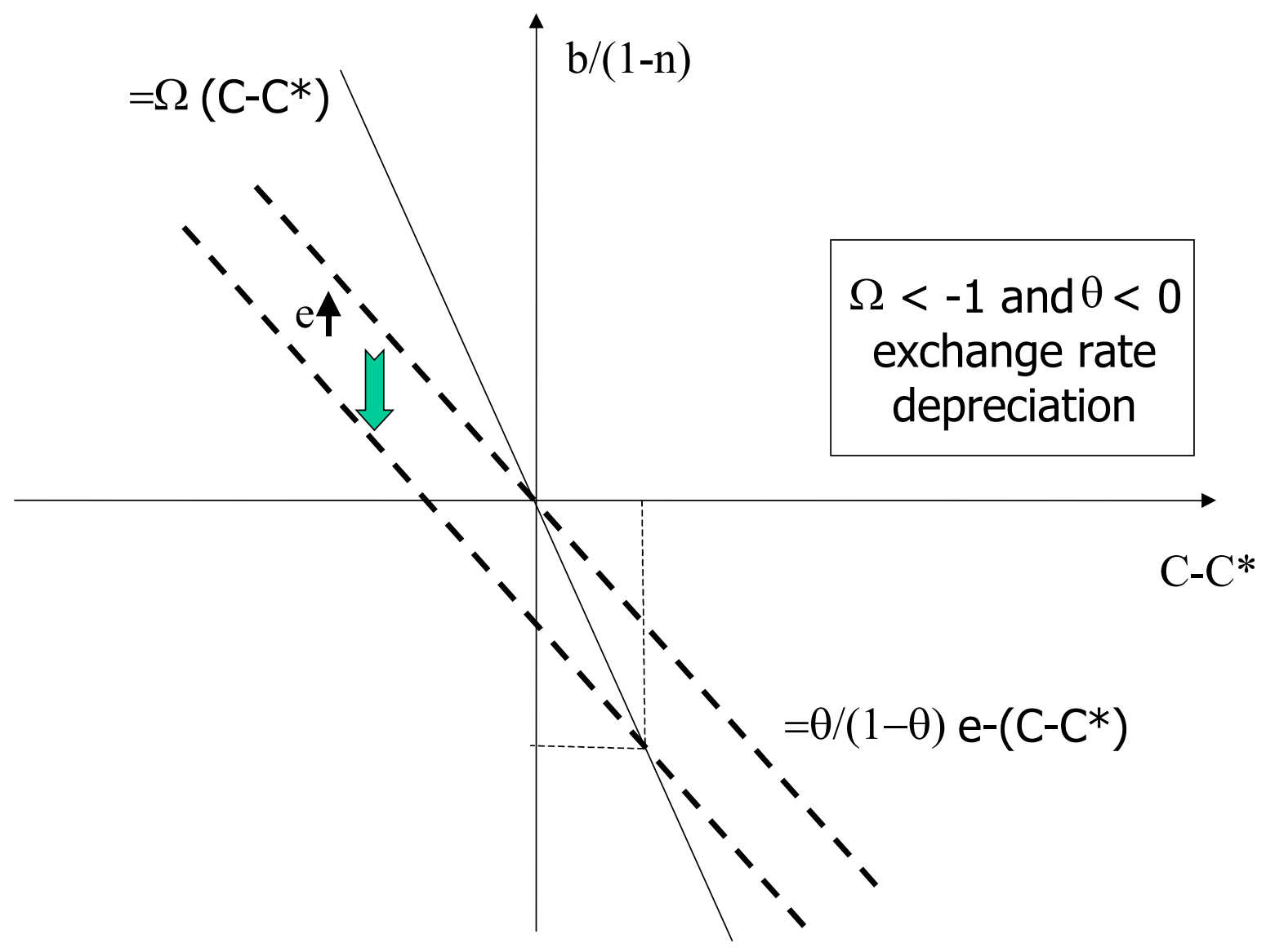

Figure 3 


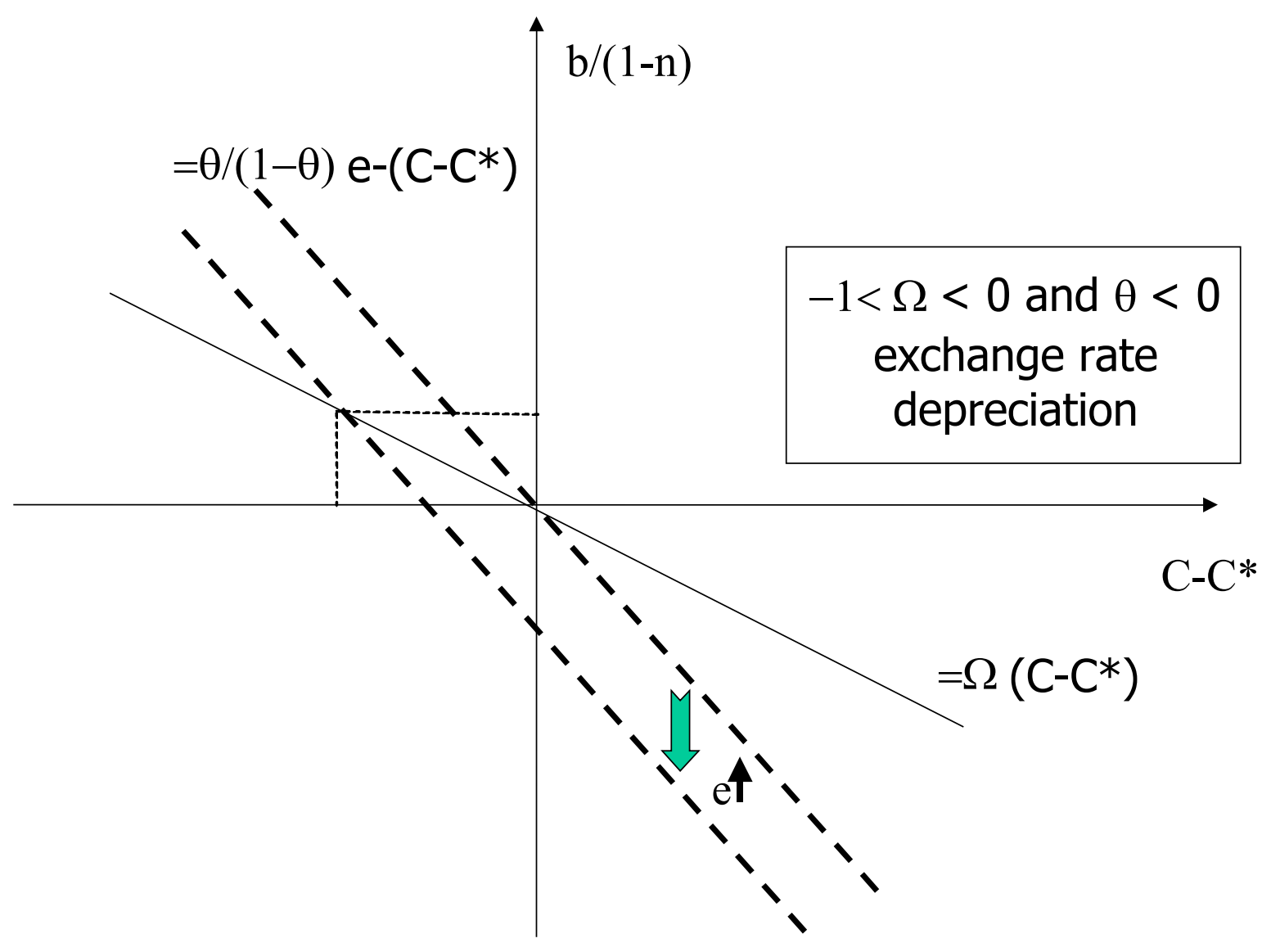

Figure 4 


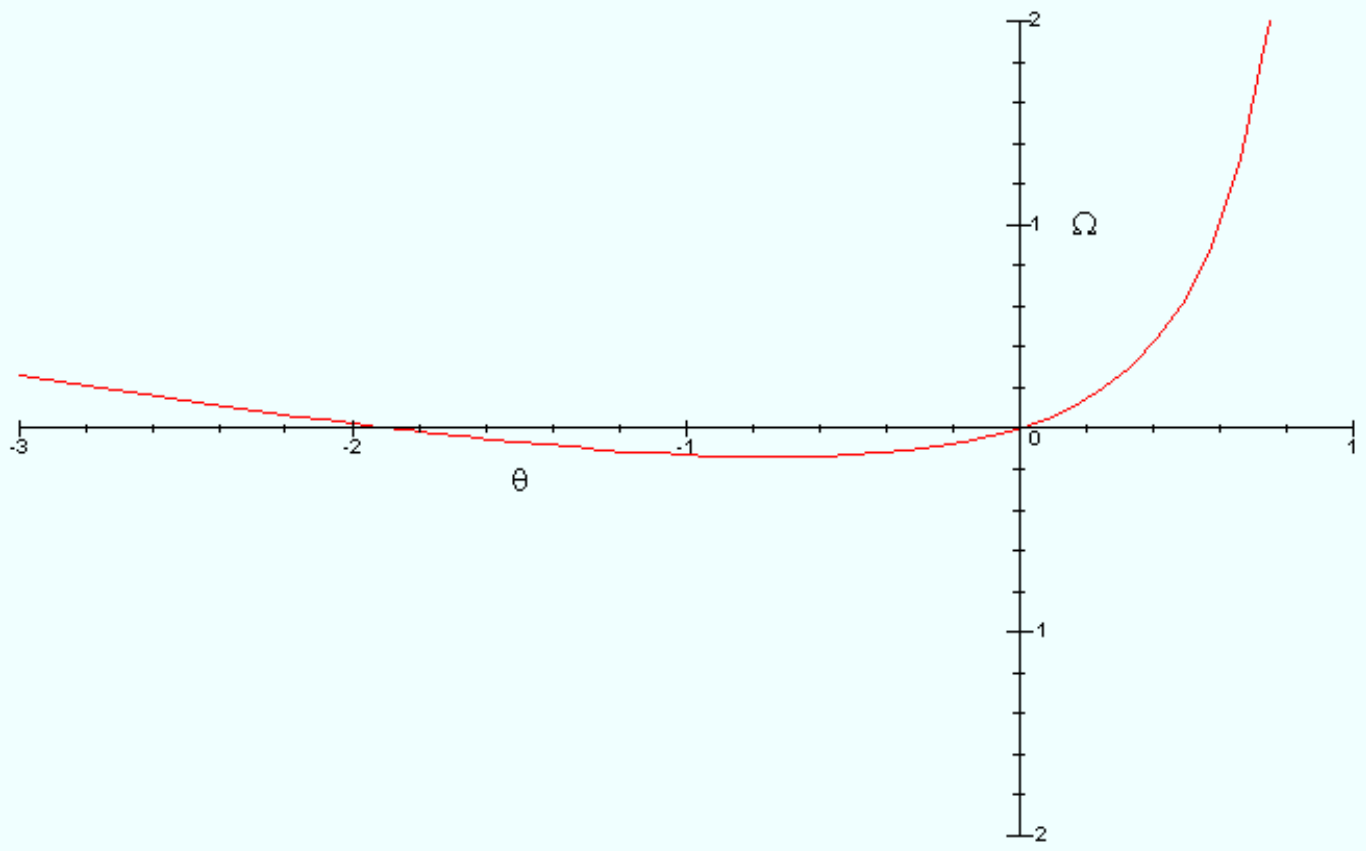

Figure 5: The ML condition when $\sigma \in(1,1+\delta)$ 


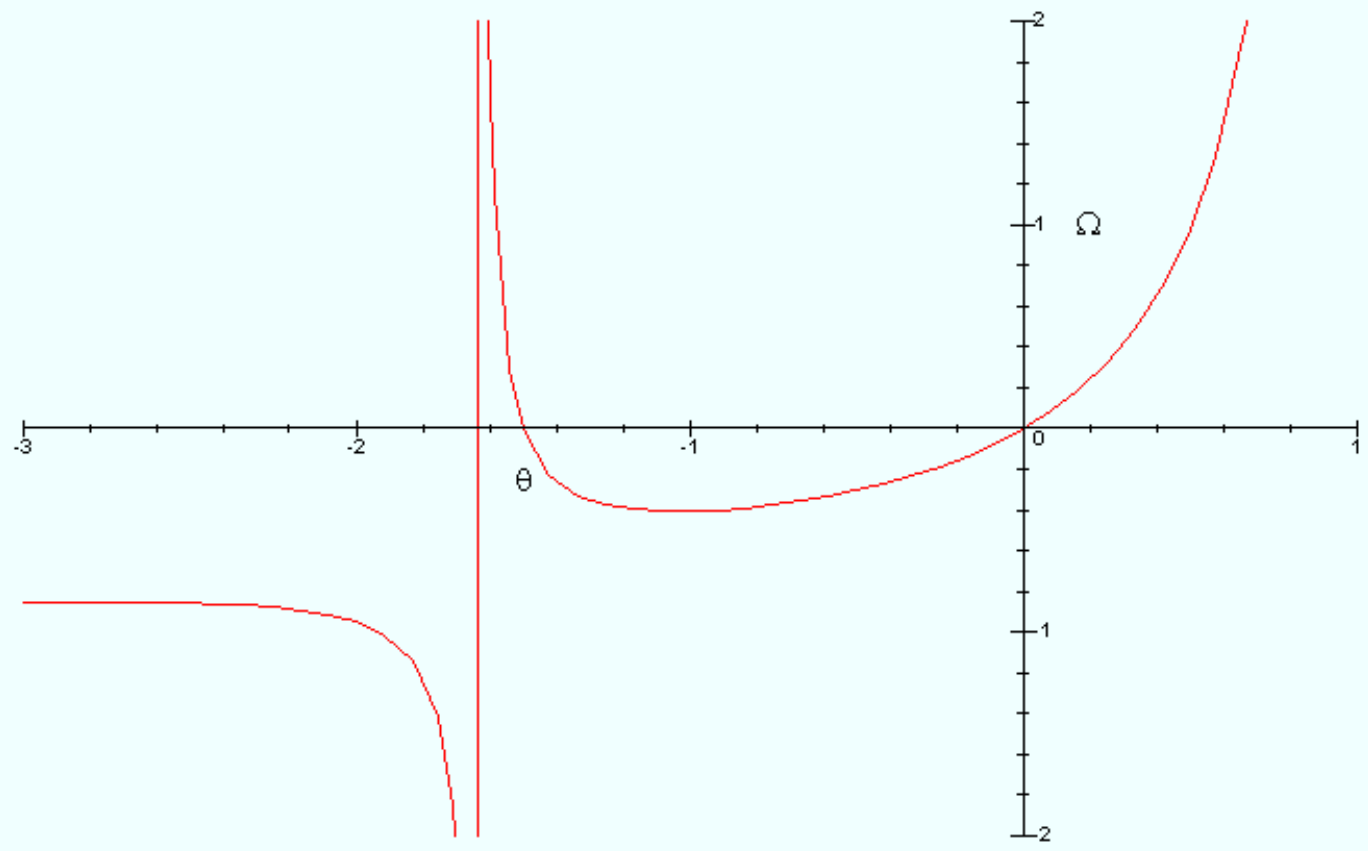

Figure 6: Trade balance response to monetary shocks 